\title{
AB0990 AUTOMATED ULTRASOUND FOR THE DETECTION OF SYNOVITIS IN THE FEET OF PATIENTS WITH RHEUMATOID ARTHRITIS (RA)
}

M. Witt ${ }^{1}$, J. Frielinghausen ${ }^{1}$, D.A. Clevert ${ }^{2}$, J. Leipe ${ }^{1}$, H. Schulze-koops ${ }^{1}$, R.B. Mueller ${ }^{3}$, M. Grünke ${ }^{1}{ }^{1}$ Division of Rheumatology, Medizinische Klinik und Poliklinik IV, University of Munich; ${ }^{2}$ Department of Clinical Radiology, University of Munich, München, Germany; ${ }^{3}$ Division of Rheumatology, Kantonsspital St. Gallen, St. Gallen, Switzerland

Background: The automated breast volume scanner (ABVS), which was developed to acquire series of consecutive B-mode pictures of the female breast, has been used successfully for the detection of synovitis in finger joints of RA patients.

Objectives: To evaluate whether ABVS can be used for the detection of synovitis in foot joints of RA patients.

Methods: 30 patients with RA were examined clinically and by manual high resolution ultrasound. ABVS was conducted using the ACUSON S2000TM. The ABVS transducer was equipped with a linear array (5 - $14 \mathrm{MHz}$ band width); the frequency was set at $11 \mathrm{MHz}$. Each automatic sweep of the scanner generated $15.4 \times 16.8 \mathrm{~cm} \times$ maximum $3 \mathrm{~cm}$ volume data sets. The system was set to perform an automatic scanning time of $65 \mathrm{~s}$ per scan with a slice thickness of $0.5 \mathrm{~mm}$. Results: 30 patients with RA were examined. 23 of them were female, the mean age was 63 years, the mean DAS28 was 4.55 with mean 8.7 tender and 7.3 swollen joints. The feet were not evaluable due to metatarsophalangeal (MTP) joint resection or gross deformity in 10 patients, resulting in 200 evaluable MTP joints. Swelling was detected by clinical examination in $13 \%$ of all MTPs. Manual ultrasound revealed swelling in $25 \%$, the ABVS in $27 \%$ of the MTP joints.

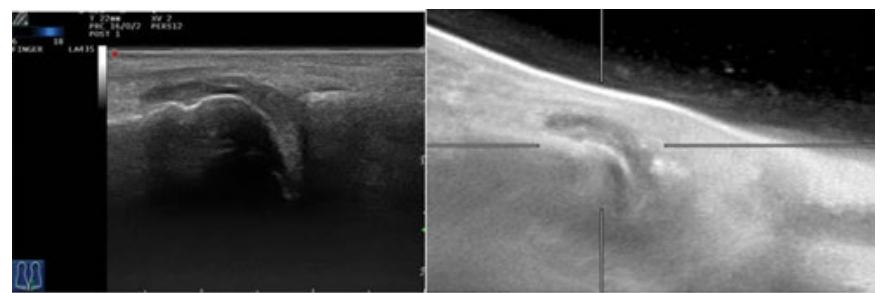

Figure: Synovits in an MTP II joint detected by manual ultrasound (left) and ABVS (right).

Conclusions: ABVS is a simple and time sparing option for effective detection of small joint synovitis not only in the hands but also the feet of patients with RA.

Disclosure of Interest: None declared

DOI: 10.1136/annrheumdis-2014-eular.3742 